\title{
O ENSINO DE FILOSOFIA: UM CONJUNTO SISTEMÁTICO DE IDEIAS
}

André Santiago Baldan, Genivaldo de Souza Santos

Universidade do Oeste Paulista - UNOESTE. Mestrado em Educação, Presidente Prudente - SP. E-mail: andre baldan@hotmail.com

\section{RESUMO}

Este artigo tem como objetivo apresentar uma concepção possível quanto à questão o que é o ensino de filosofia? Apresentamos a resposta hegeliana para esta querela, partindo de obras e comentários sobre Georg Wilhelm Friedrich Hegel. Veremos que o ensino de filosofia aparece como o ensino de diversos tópicos históricos da filosofia. Esta concepção nos auxilia a visualizar objetivos para a disciplina de filosofia nas salas de aula de ensino médio brasileiras. A preocupação com o tema do ensino de filosofia é relevante visto que tivemos, na história da educação brasileira, a retirada da disciplina de filosofia das escolas na década de 70 e, com a Lei de Diretrizes e Bases 9394/96, tivemos o retorno desta disciplina para o ensino médio. Este trabalho visa então trazer à luz a concepção hegeliana para este assunto que é tão vivo na educação brasileira: o que é isso, o ensino de filosofia?

Palavras - chave: Ensino de filosofia. Ensino médio. Filosofia. Hegel. História.

\section{TEACHING PHILOSOPHY: A SET OF SYSTEMATIC IDEAS}

\begin{abstract}
This article aims to present a question as possible to the question what is the teaching of philosophy? We present the hegelian answer for this complaint, beginning of works and commentary about Georg Wilhelm Friedrich Hegel. We will see that the teaching of philosophy appears as teaching various historical philosophy topics. This conception help us to view objectives for the discipline of philosophy in the classrooms brazilian's high school. The concern with the theme of teaching philosophy is relevant as it had in the history of brazilian education, the withdrawal of the discipline of philosophy of the schools in the 70s and with the Law of Guidelines and Bases 9394/96, we had the return of this discipline to the school. This work aims to bring to light then the hegelian conception for this subject that is so alive in brazilian education: what it is, the teaching of philosophy?
\end{abstract}

Keywords: Teaching philosophy. Secondary school. Philosophy. Hegel. History. 


\section{CONSIDERAÇÕES INICIAIS}

É evidente o interesse da filosofia pela educação em toda sua história. Temos, na filosofia clássica, a preocupação de Sócrates e de Platão em esclarecer conceitos e propor modelos educativos em seus diálogos; na filosofia medieval temos a filosofia escolástica, que deu base para o método utilizado na formação cultural e religiosa de seu tempo; há também o projeto humanista, da filosofia renascentista, que levava as preocupações filosóficas a centrarem-se no ideal de homem; na filosofia moderna há o iluminismo, que se preocupava em tirar o homem da ignorância. Tais preocupações da filosofia com a educação permanecem válidas até o final da primeira metade do século XX onde, devido influencia positivista, as preocupações filosóficas se voltaram a exercícios puramente lógicos, afastando-se das preocupações pedagógicas. (SEVERINO, 1990; DALBOSCO, 2009)

No Brasil, tivemos três períodos de destaque no que se refere ao ensino de filosofia. 0 ensino de filosofia no século XX onde se ensinava "A Filosofia" que era "[...] constituída por conteúdos como Lógica, Metafísica, História da Filosofia [...]" (TOMAZETTI, 2012. p. 231) e foi retirada das salas de aula de ensino médio na década de $70^{1}$. O período dos anos 80 até a Lei de Diretrizes e Bases (LDB) n. 9.394/96 caracterizado pela luta do retorno do ensino de filosofia às salas de aula, apontando como objetivo da filosofia "[...] ensinar o aluno a ser crítico de seu tempo [...]" (TOMAZETTI, 2012. p. 231); com a LDB n. 9.394/96 a conquista veio de forma tímida onde se apontava a importância para alguns conhecimentos transversais.

Atualmente, vivenciamos o terceiro período, caracterizado pela luta da obrigatoriedade da disciplina de filosofia nas salas de aula do ensino médio brasileiro ${ }^{2}$ e pelos desafios do seu ensino no ensino médio: "o que" ensinar e "como" ensinar filosofia no contexto escolar? Em parte, estes problemas ocorrem porque não há concepção consensual do que é a filosofia.

Com tais problemas em foco e cientes de que existe uma pluralidade de concepções quanto o ensino de filosofia (FÁVERO, CEPPAS, GONTIJO et al. 2004 ; GELAMO, 2008 e 2009; NOVELI, 2005; SILVEIRA, 2011), executamos um levantamento bibliográfico objetivando a compreensão da concepção hegeliana sobre o ensino de filosofia, onde o autor estabelece o ensino de filosofia como ensinar um conjunto sistemático de ideias.

\footnotetext{
${ }^{1}$ Em 1961, a partir do Decreto de Lei n. 4.024/61, a filosofia deixou de ser obrigatória no ensino, mas foi com o Decreto de Lei 869/69, regulamentado pelo Decreto 68.065/71, que a filosofia sai definitivamente do currículo do segundo grau, dando lugar para a Educação Moral e Cívica e OSPB.

${ }^{2}$ Essa luta para a obrigatoriedade do ensino de Filosofia na matriz curricular do ensino médio obteve êxito com a promulgação da Lei n. 11.684/2008 que alterou a Lei n. 9.394/1996 no artigo 36 (BRASIL, 2008)
} 


\section{A FILOSOFIA COMO UM CONJUNTO SISTEMÁTICO DE IDEIAS}

Hegel esteve fortemente envolvimento com a educação de seu tempo, apesar de nunca ter escrito nenhum tratado especificamente sobre este assunto, quando o filósofo esteve à frente do colégio de Nurnberg, como diretor e professor de filosofia (1806-1816), escreveu três textos relacionados à estrutura educacional de sua época. O primeiro texto, que trata essencialmente do que significa para os jovens ginasiais terem a possibilidade de estudar filosofia, “[...] é um parecer elaborado para o real conselheiro superior da Baviera, Immanuel Niethammer [...]" (NOVELLI, 2005. p. 130). O segundo texto, cujo teor se refere aos conflitos existentes entre forma e conteúdo, é também uma carta ao real conselheiro superior Niethammer. Por fim, o terceiro texto é uma carta enviada a Friedrich v. Raumer professor e real conselheiro do governo prussiano, abordando o tema do ensino de filosofia nas instituições superiores.

O filósofo não possuía apreço pelas tendências pedagógicas que the eram contemporâneas, pois se preocupavam "[...] com situações periféricas em relação à educação que se traduziam na concentração sobre os métodos e as técnicas [...]" (NOVELLI, 2005, p. 132). Para ele as preocupações com o homem em um momento pontual não são de importância, tais preocupações deveriam voltar-se para um homem focado em tudo o que ocorre: "O homem se caracteriza por se construir e ao fazê-lo ele acaba por construir seu próprio mundo [...]" (NOVELLI, 2005, p. 132). Mesmo com dúvidas acerca da permanência do ensino de filosofia no ginásio Hegel dá grande atenção ao assunto, que chegou a ser sua ocupação quando veio a se tornar Diretor e professor de ciências filosóficas preparatórias no Ginásio de Nuremberg.

Hegel indica que o exercício filosófico ocorre através da exposição do educando a "[...] modos mais elevados de pensamento [...]" (GELAMO, 2008, p. 156), trazendo conteúdos ligados à história da filosofia para as salas de aula ginasiais, desta forma o autor indica que o filosofar não é um mero refletir sobre algo, o ato de utilizar a razão não é suficiente para poder emitir um juízo gerado por atividade filosófica, a filosofia é fruto de reflexão e analise, onde a filosofia não deve ser rebaixada ao povo, mas sim "[...] o povo deveria ser elevado ao nível da filosofia [...]" (NOVELLI, 2005, p. 136).

Há ainda a preocupação do autor em formular um mapa de conteúdos a serem abordados de forma que parta de algo existente até chegarem ao pensamento conceitual, o conteúdo é pensado para que o aluno inicie seus estudos de filosofia com temas ligados ao seu dia a dia e possa, gradativamente, vir a estudar os mais abstratos conceitos filosóficos. Hegel indica que o ensino de filosofia deveria ser divido em três etapas: na primeira etapa formativa, correspondente ao primeiro ano do ginásio, o foco da disciplina de filosofia seria o ensino de direito, da moral e da 
religião; na segunda etapa, correspondente a dois anos de estudos, o estudo se volta à lógica, a metafísica e a psicologia; na terceira etapa, correspondente ao último ano do ginásio, o aluno deveria ser exposto ao estudo enciclopédico, universal, da filosofia e, como ato de deleite intelectual, o professor poderia trabalhar estética com seus alunos ao final do curso.

Com esta postura o filósofo procura estabelecer conteúdos ao ensino de filosofia, evitando que este seja algo voluntarioso ou um pensar sobre algo; a primeira etapa proposta por Hegel vem em conformidade com a normativa de sua época, pensando o ensino de filosofia de modo introdutório, tendo início naquilo que, ao aluno, parece próximo. Na segunda etapa o filósofo, como nos indica Gelamo (2008), Hegel parece concordar que estudo da lógica baseie-se na lógica kantiana, porém, posteriormente, os estudos sobre a lógica devem centrar-se sobre sua Lógica objetiva $^{3}$, pois esta consiste na superação da lógica formal e da lógica kantiana; ao que concerne aos estudos metafísicos Hegel posiciona-se a favor de estudos ligados às obras de Immanuel Kant. Passando pela lógica e pela metafísica, Hegel postula como conteúdo posterior a psicologia, que é a mais abstrata das três temáticas e por isso deve vir por último; esse tema deve ser abordado cuidadosamente visto que para o filósofo o estudo de psicologia nessa fase pode ser danoso à formação do individuo. Os estudos sobre psicologia devem ser divididos em duas partes: a primeira, a manifestação do espírito, com estudos voltados a autoconsciência e a razão; e, a segunda parte, do espírito em-si e para-si, onde o "[...] objetivo explicitar a relação do espírito consigo mesmo [...]" (GELAMO, 2008, p. 158).

Na última fase dos estudos Hegel estabelece a importância em abordar apenas conteúdos estritamente filosóficos, reservando-se, assim, aos estudos enciclopédicos; que o filósofo restringe "[...] a lógica, a filosofia da natureza e a filosofia do espírito [...]" (GELAMO, 2008, p. 158). Ao final desse último ano de estudo Hegel indica um estudo mais agradável ao aluno, a estética. Ainda no que se refere aos conteúdos de filosofia, o filósofo aponta grande importância para o estudo dos clássicos, a filosofia grega, visto que estes trabalham com grande destreza assuntos relacionados à formação do homem:

"O homem derivado do mundo grego é aquele que se direciona para a eticidade, pela razão e pelo espírito despojado de suas contingências. Saber e conhecer o que os gregos sabiam e conheciam significa garantir a formação de homens guiados pela razão e pelo espírito." (NOVELLI, 2005. p. 134).

\footnotetext{
${ }^{3}$ Hegel refere-se à primeira parte da obra Ciencia de la Logica (1993).
} 


\section{CONSIDERAÇÕES FINAIS}

O ensino de filosofia aparece então como o ensino de um conjunto sistemático de idéias baseados na história da filosofia. Percebemos também a clara preocupação de Hegel em elaborar conteúdos de filosofia de forma que eles possibilitem clareza ao trabalho do professor, auxiliando o aluno a visualizar a filosofia em sua vida e gradativamente adquirir gosto por ela; desta forma os alunos teriam contato com os pensamentos realizados por grandes mentes da história da humanidade, conheceriam o filosofar de vários autores e estariam mais capacitados e habilitados ao seu próprio exercício de pensar.

Visto a teoria de Hegel percebemos nas Orientações Curriculares Nacionais Conhecimentos De Filosofia (BRASIL, 2006) uma clara tentativa de utilizar a teoria hegeliana quando propõem que o ensino de filosofia estimule o filosofar e o pensar por meio do estudo histórico da filosofia. As Orientações Curriculares Nacionais citam Silvio Gallo (2012) para amparar essa proposta de ensino de filosofia: "[...] só se pode filosofar pela História da Filosofia, e só se faz história filosófica da Filosofia [...]" (BRASIL, 2006. p.32). Essa proposta deixa a entender que o ensino de filosofia nas escolas de ensino médio brasileiras deve vincular o ato do filosofar com a história da filosofia, utilizando este espaço para realizar atividades e exercícios com o objetivo de estimular os alunos a pensar filosoficamente, amparados pela história da filosofia.

\section{REFERÊNCIAS}

BRASIL, Ministério de Educação e Cultura. $L D B n^{0}$ 9.394/1996, de 20 de Dezembro de 1996. Estabelece as diretrizes e bases da Educação Nacional. Brasília: MEC, 1996. Disponível em: http://portal.mec.gov.br/arquivos/pdf/ldb.pdf. Acessado em 6 Abr. 2013, às 13 horas e 18 minutos.

BRASIL, Ministério da Educação. Secretaria de Educação Básica. Ciências humanas e suas tecnologias. Brasília, DF, 2006. (Orientações Curriculares para o Ensino Médio; v.3).

Dalbosco, Cláudio A. Por uma filosofia da educação transformada. Anped 2009. Disponível em: http://www.anped.org.br/app/webroot/reunioes/32ra/arquivos/trabalhos/GT17-5336-Int.pdf.

Acessado no dia 03, Mai. 2013,ás 13 horas e 20 minutos.

FAVERO, A. A. CEPPAS, F. GONTIJO, P. E. et al. O ensino de Filosofia no Brasil: um mapa das condições atuais. Caderno Cedes, Campinas, vol. 24, n. 64, p. 257-284, set./dez. 2004. Disponível em: http://www.scielo.br/pdf/ccedes/v24n64/22830.pdf. Acessado em 7 Abr. 2013, às 14 horas e 23 minutos.

GALLO, S. Metodologia do ensino de filosofia: Uma didática para o ensino médio. Campinas - SP: Papirus, 2012. 
GELAMO, R. P. O Ensino da filosofia e o papel do professor-filósofo em Hegel. Trans/Form/Ação, São Paulo. v. 31. n. 2., p. 153-166, 2008. Disponível em: http://www2.marilia.unesp.br/revistas/index.php/transformacao/article/viewFile/987/890.

Acessado no dia 6 Mar. 2013, às 16 horas e 58 minutos.

GELAMO, R. P. O ensino da filosofia no limiar da contemporaneidade : o que faz o filósofo quando seu ofício é ser professor de filosofia. Tese (Doutorado em Educação) - Faculdade de Filosofia e Ciências, Universidade Estadual Paulista: Marília, 2009. Disponível em: http://www.marilia.unesp.br/Home/Pos-

Graduacao/Educacao/Dissertacoes/gelamo rp dr mar.pdf. Acessado no dia 13 Mai. 2013, às 22 horas e 13 minutos.

HEGEL, George Wilhelm Friedrich. Ciencia de la Logica. 2 vol. 6a ed. Trad: Augusta e Rodolfo Modolfo. Buenos Aires: Librarie Hachette, 1993.

NOVELLI, P. G. A. O ensino da filosofia segundo Hegel: contribuições para a atualidade. Trans/Form/Ação, São Paulo. v. 28. n. 2., p. 129-148, 2005. Disponível em: http://www.scielo.br/scielo.php?script=sci arttext\&pid=S0101-31732005000200009. Acessado no dia 3 Abr. 2013, às 17 horas e 50 minutos.

SEVERINO, A. J. A contribuição da filosofia para a educação. Aberto. Brasilia, ano 9. n 45. jan mar. 1990. Disponível em: http://emaberto.inep.gov.br/index.php/emaberto/article/viewFile/717/640. Acessado no dia 6 de Ago. 2014, às 11 horas e 9 minutos.

SILVEIRA, R. J. T. Ensino de Filosofia de uma perspectiva histórico-problematizadora. Educação em Revista, Marília, v.12, n.1, p.139-154, Jan.-Jun., 2011. Disponível em: http://www2.marilia.unesp.br/revistas/index.php/educacaoemrevista/article/viewFile/1544/1338 . Acessado em 8 Abr. 2013, às 15 horas e 19 minutos.

TOMAZETTI, E. M. Formação e Arte de viver: o que se ensina quando se ensina Filosofia?. In. BUENO, S. F. PAGNI, P. A. GELAMO, R. P. (org.). Biopolítica, arte de viver e educação. Marília: Oficina Universitária, São Paulo: Cultura Acadêmica, 2012. p. 229-247. 